\title{
ERROR CORRECTION, FEEDBACK, AND ACTION RESEARCH IN AMERICAN LITERATURE CLASSROOM: WHY NOT?
}

\author{
Didik Murwantono \\ Sultan Agung Islamic University (UNISSULA) \\ Semarang, Indonesia \\ didik_025@yahoo.com
}

\begin{abstract}
Error correction and feedback are two indispensable factors in shaping literature technique and theory. In this case, these techniques were applied to students who took American Multicultural Literature at College of Languages, UNISSULA Semarang. The students were asked to make any literary criticism toward several literary works from different cultural backgrounds. Both teacher and students have significant roles in those preferences. If teacher and students both understand the purpose of certain correction techniques and agree their use, feedback is more likely to be productive. This article also covers action research by using two cycles. It finds that students can improve their capabilities and skills in writing of an intellectual diary. It can be seen from the result of observation both test-1 and test-2 which had the progress in index from 0.45 to 0.52 . Hence collaborative writing and reader-response criticism has given great contribution toward students' motivation in learning American literature.
\end{abstract}

Keywords: Error correction, feedback, writing, technique, literary criticism

\section{INTRODUCTION}

Writing is one of significant English skills along with listening, speaking, and reading. It is not any easy and frightening job. It means that anyone can do that as long as he is fervent to learn. Both writing and reading are two indispensable points. Some researches show that mostly the process in writing is initiated from the process of reading. The style of language will also be greatly influenced from how far the quality of reading influences it. It means that reading habit seems to be positively correlated with writing proficiency and quality.

Reading is a process of taking in information and it will extensively contribute to students' creativities. "Reading is an equal to thinking by borrowing someone's thought" (Hernowo, 2003: 35). By reading, someone can comprehend one's thought and apply it to his experience and thought. Eminence reading is not only to read word by word, but also to focus generally on the meaning of what is being read than on the language. Shortly, we can feel, think, and know 
what the book contains. Here, it is necessary to have creativity on verbal and non-verbal communication (writing) to build ideas and thoughts through writing toward public.

Reading and writing are like two sides of a coin. They are very useful for students to comprehend any phenomenon in literary work. Therefore, the writer always encourages my students to take time out to read in everywhere. The writer summaries that skilled writers are those who such as (1) did pleasure reading; (2) read books, newspaper, literary works more, and (3) had more books and articles (printed or online sources).

Having done an observation for the fifth semester of American Literature class in the last semester, the writer found that UNISSULA's students in American literature class had faced many obstacles in giving their perspectives and interpretations toward some literary works. Moreover, the students continued to suffer from various problems preventing them to participate actively in the classes. It means that the students lack for the competition in studying literature. How to accelerate the literature class becomes the better one. One of them is by knowing the main obstacles and by waving those problems so that students can study and participate well in the class. Individual assignment is one of alternatives in handling the problems.

The context individualism here is not equal to egoism or selfishness, but it is dedicated to the concept of responsibility. It means students have responsibilities toward their successes based on their capabilities, efforts, or even finance by themselves. So, individual assignment is well prototypical. Each individual with his capital has own individual responsibility to complete some given assignments. The teacher gives full creativities in building their ideas and thoughts into good writing. It is also any kind of challenge for them to competitive with others.

Hence the roles of teacher here are to highlight on the tasked-materials; to give correct instructions toward the assignments; to analyze their work as well as to give feedback and error correction. In Western and America, individual assignment is well known as an 'intellectual diary'-the writer's experience in American Studies--cause this assignment must be submitted and discussed to cover the overall problems in the issue or topic accurately.

Writing skills for this assignment are also necessary to ignore the grammatical errors, hence the writing of paragraphs can be understood as a 
Journal of English Education, Literature, and Culture

whole idea completely. The writer initiates from some researches due to error correction and feedback to reveal some ideas in this paper writing. Even though the research evidence on the effects of error correction on students' writing skills is far from conclusive. Several research studies investigating the effects of different types of feedback on undergraduate students' writing have suggested that 'explicit error correction of surface-level errors (spelling, punctuation, grammar) seems to be generally ineffective' (Huntley, 1992; Leki, 1990). Truscott (1996: 5) goes even farther to conclude that 'this type of correction should be abandoned in writing classes because it can harmful effects.' On the other hand, the research generally does advocate feedback on 'the student writer's handling of content and organization' (Fathman and Whalley 1990). There is evidence that such feedback is necessary and does result in improved student writing.

Most people assume that the concept of reflective thought has had an influence on teacher throughout the twentieth century. 'Reflective thinking can be viewed as thoughtful, self-questioning of teachers' actions, experience, or attitudes (Moon and Boullon, 1977). If, for example, teachers are not satisfied with the learning success of their students or the value of their procedures, adherents of reflective thinking would argue that the teachers should plan and organize acts or processes to help them address such concerns.

To give structure to the process of reflection and inquiry, the systematic method called 'Action Research' can be applied (Wallace, 1998). Therefore, the writer highlights on the application of action research in his class. This methodology refers to classroom investigation initiated by researchers, perhaps teachers, who look critically their own practice with the purpose of understanding and improving their teaching, and the quality of education.

\section{DISCUSSION}

\section{Action Research}

Reframing is a fundamental concept in professional development; 'teachers are more likely to learn when reflecting on and testing personal theories' (Roberth, 1998). A reflective model for such research attempts to connect received-knowledge, such as facts, data, and theories, with experiential knowledge-what we know from our practical, professional experience-by a continuous process of reflection. 'This reflective cycle may occur before, during, 

or after an event in a process of recollection as we struggle with a problem' (Wallace, 1991).

To solve classroom problems, teachers can resort to Action research, ' $a$ method that formalizes reflection by engaging the practitioners in a critical and reflective attitude' (Nunan, 1990). Teachers applying action research attempt to answer questions related to some aspects of their professional practice; to do so they collect and analyze data, reflect on what they discover, and then apply it to their professional practice.

By borrowing the writing of Richards and Lockhart (1994), the cycle of action research includes the following stages: 'initial reflection to identify an issue or problem, planning an action (to solve the problem), implementation of the action, observation of action, and reflection on the observations.' The cycle is shown below:

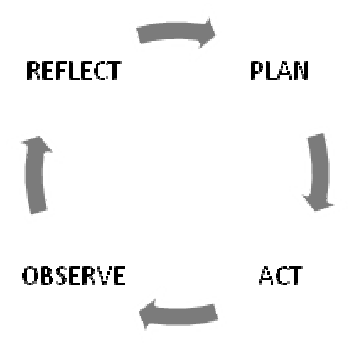

Figure 1. The cycle of action research

(Source: Richards, J.C. and C. Lockhart. 1994. Reflective Teaching in Second Language Classrooms)

To illustrate the cycle, assume you are a teacher who has perceived a need or a problem with a class you are teaching (initial reflection) - that is, you have noticed that your students become quite (can't write anything well) whenever they give a sample of writing. You reflect on what you see in your classroom and make a detailed plan of action to improve your professional practice. In doing so, you make your implicit criteria and beliefs explicit and design activities to broaden your students' strategies for handling writing techniques.

Then you prepare (plan) the information-gathering instruments you will use, such as tests, questionnaires, and interviews. You carry out your plan (act) in light of your past experience of such situations, social landscape, and 
feedback from your students, and you collect data, using the techniques you planned. After the data are collected, you analyze your findings. For example, one of your students might mention that a particular strategy (a collaborative writing, for example) you taught them was very helpful. At the end of this cycle, you reflect on what has happened so that experiential knowledge can feedback into received knowledge.

In other words, you reconstruct your knowledge through reflection. For example, you might ponder how effective the changes you made in your teaching practice were, what you learned from the changes you made, or what barriers to change existed. 'Reflecting on barriers to change will likely lead you to continue the action research cycle' (Richards and Lockhart, 1994). In addition, some theories and approaches are necessary to support in handling problems related to action research. Some of them are in the following sub-chapters.

Theories and Techniques

\section{Social Construction}

By borrowing the writing of Richards and Lockhart (1994), 'the constructivist theory was framed in terms of individuals, disregarding that each person's development occurs in constant exchange with his or her social circumstances', such as immediate working relationships, the climate of the schools attended, and other environmental factors. We know today, however, that learners develop their sense of the world through social interactions. Similarly, teachers' beliefs emerge from a complex of social and individual influences, including their own experiences, public educational theories, and the teachers' relationships with their students, colleagues, and superiors. This new perspective, known as social constructivism, considers the act of learning to be more than the construction of new meanings. In fact, it results from a dynamic interaction between personal change and social circumstances, and it involves cognition as well as feelings.

An adequate view of teacher learning, therefore, should recognize this connection between internal development and the person's landscape. This social element implies that the social constructivist perception recognizes collaborative dialogue and talk to be central to the process of continual 
Journal of English Education, Literature, and Culture

intellectual, experiential and attitudinal growth of teachers. The collaboration required to do this provides teachers with rich opportunities to understand their tacit knowledge and support changing views of themselves as teachers.

\section{Collaborative Writing through Reader-Response Criticism}

How to respond to student writing is a unique topic in literature class. Indeed, several studies have investigated the effects of various types of teacher feedback on students' writing skills, but little research has explored instructors' and students' preferences for feedback and error correction. This paper is by no means a comprehensive account of writing or more accurately, error correction and feedback in the classroom. In fact, it is intended to be more suggestive than comprehensive though it is characterized by more summary than research analysis. Shortly, it is based on merely the writer's experiences in one American Multicultural Literature class at College of Languages, UNISSULA Semarang.

The writer got one class with around 10 students in American Multicultural Literature class last semester. It means that the writer had to take any strategy to handle it effectively. At least, the suitable method was greatly needed. Research has shown that collaborative writing is an effective to handle the class. The writer assumes that through collaborative practice in groups, students were empowered to develop confidence, authorship and enjoyment of being part of the writer community. In the similar perspective, Anshari (2004) experimented a four-cycle workshop model of collaborative writing in the Department of Indonesian Literature of UPI. His study has reconfirmed more or less the similar finding as follows: "Students became more enable to solve the writer's block, more productive, mature in style, and more confident to publish."

Another approach is literary approach. A work of literature is any reflection of events or phenomena in a society. Hence the study of literature is very crucial because it exposes to meaningful contexts that are full with descriptive language and characters in line with the spirit of era at the time. "As with sociology, literature is pre-eminently concerned with man's social world, his adaptation to it, and his desire to change it" (Laurenson and Swingewood, 1972: 13). In short, literature provides a mirror to the age as reflected from literary works.

A literary approach which is suitable with the class is Reader-Response Criticism. This approach focuses on beginnings-how the ways a teacher can draw out in the classroom readers' responses to a text. It proposes strategies 
Journal of English Education, Literature, and Culture through which teachers initially engage students and cause them to explore their responses. They demonstrate how, although the teachers may provide the catalyst to open the discussion, it is the students' responses that are at the heart of the activity.

In this approach we see teachers resist using techniques that have the effect of predicting or directing response, thus limiting responses, such as reference to the writer's turn of mind or critics' understanding of the text. This research offers a variety of approaches for initiating reader response and they illustrate a range of audiences and situations. The strategies described were selected in each case because they fit specific teaching occasions, but they may be adapted to other audiences and situations. Readers are invited to adapt these strategies to their own teaching situations and to think about how they can use them in their future classrooms.

This research also used film as literature. Film in the classroom was positioned as the central focus for response, although the writer acknowledged the value of using film adaptations in concert with teaching novels. I raised the challenge of what to teach about film in the first place, offering choices that follow the conventional paradigms of literature, but I established the meaningful appropriateness of a primary reader-response approach. The students' responses were heated and oppositional along gender lines. The developmental stages of the discussion were expressed to reveal the students' emerging understanding, their tentative rapprochement, revealing also my role as catalyst.

Applying Action Research to Teacher Development

One goal of teacher development is to facilitate awareness through reflection. What does this mean in practice? I attempted to answer this question by illustrating how I respond to a problem in my writing class. In my discussion, I applied Richards and Lockhart's cycle of Action research.

Initial Reflection: A Problem

To reflect on my attitude and my role in the classroom, I put on the record a lesson. When I reviewed the recording, I realized I had controlled and 
Journal of English Education, Literature, and Culture

directed the lesson all the time. Despite the fact that my students had been working in groups that day, I had not played a consultant role to help my students become self-directed. My students were constantly asking me questions such as, "Can you come, please?" or "Can you help us?" or "What's the meaning of ...?"

My problem, as I perceived it, was that my students were overly dependent on me, trying to understand what I might have been doing to encourage such dependency. I decided to examine the beliefs that underlie my actions in the classroom. I first had to come to terms with the fact I was a teacher who liked to have everything under control; I had not been taught that the teacher is not the center of the world. My personality and the role I played in the classroom seemed to affirm teacher-centered methods, which I knew from research are likely to inhibit learner's independence.

However, I do believe in the advantages of student-centered classrooms, and I would like to be a guide rather than the person who "knows it all". When I reflected on my actions in the classroom, it was apparent that my personality and prior experiences were in conflict with my beliefs about teaching and learning. I saw a need to reflect deeply to establish an agreement between my beliefs and my actions in the classroom.

In such reflection a way to cause change in a teachers' behavior? Is it possible for a teacher who likes to have everything under control to increase autonomy in learners? To answer these questions, I made "planning decisions" as a way to take action and identify opportunities to change aspects of my work. Before conducting the research, there was a preliminary test $(\mathrm{t}-0)$ for getting the strong supporting data. This research consisted of two cycles. The first cycle was for six meetings with the materials of American, European, and African writers. Each meeting had one intellectual diary and it would be discussed in the following meeting. There were error corrections per meeting and feedbacks. The first test ( $t-1)$ was conducted in the seventh meeting. Meanwhile the second cycle was six meetings aftermath the mid-semester term. In this session, each meeting had collaborative writing and reader-response criticism. There were also error corrections, feedbacks, observation sheet, and test-two (t-2). 
Cycle One

Planning an Action

After having an initial reflection from the condition and situation in the class, I had some plans to conduct a different treatment in teaching of American literature. There were some significant items for planning the class, such as Unit of Lecturing Course, Lecturing Course Program Outline, diaspora novels, films, intellectual diary, observation sheet, and test sheet. The first treatment was by giving the students several individual assignments to make a brief analysis toward any literary work. These assignments were dealt with their responses both perspectives and interpretations as an intellectual diary.

Implementation of the Action

Class started with a brief description about the course materials. It embraced with the skills of speaking, reading, listening, and writing. Students had a lot of time to comprehend the short stories while listening to the lecturer's summaries. At the end of the lecturing, I gave them an assignment that had to be submitted in the following session as an intellectual diary. These intellectual diaries were discussed in the class by giving error corrections and students also gave their feedbacks after the discussion. The class was openly debated. Therefore, they were very enthusiastic in giving responses toward literary works and films. The main role for teacher guided them for giving their opinions and interpretations. Teachers who exhibited a previous traditional stance in the classroom now see their role as a facilitator, a coach, or a mentor.

\section{Observation of Action}

For getting the information of the 'intellectual diary' effectiveness, hence there was a test (t-1) with the following result: the students, who had the progress in their scores, were six students from ten students (60\%). After having been compared with the initial test (t-0), in fact, it was higher with the index of $0.45(11.2 \%)$. It can be said that an intellectual diary can improve the students' skills in writing. It also motivates students to practice writing.

\section{Reflection on the Observations}

During the first cycle, the students did the assignment on time. They grasped the grammar well. They were acquainted with the tasks. Teacher was 
Journal of English Education, Literature, and Culture

closed to the students. And there was good communication in teaching between teacher and students. Based on the indicators above, there were some problems noted as follows: students were afraid of asking; the novels or the films were not interesting enough to trigger their opinions and interpretations; and the class was still not active.

The problems above can be lessened with the following actions in cycle two: students can discuss an issue with their friends through collaborative writing; teacher encourages the students not to hesitate to ask questions; teacher offers students a literary approach of reader-response criticism; and teacher writes down the guidelines of those strategies: collaborative writing and reader-response criticism.

Cycle Two

Planning an Action

The second plan along with test-two (t-2) was similar to the action one, but it focused on media both collaborative writing and reader-response criticism. Films and novels from multi-ethnics were also given to trigger students' ideas in relation to social and cultural issues. This step was dedicated for the students on how to share their experiences and capabilities in analyzing any issue of literary work.

Implementation of the Action

Based on the result of reflection on the observation one, hence in cycle two, students firstly understood the guidelines of collaborative writing and reader-response criticism. In analyzing any literary work, students were asked not to summary the story of the novels or the films, but they gave their interpretations by giving the facts based on the novels or the films.

Collaborative writing is designed to help teachers analyze student work to improve instructional decisions and thus, students' writing. As part of the system, teachers join a study group to interpret and document students' progress toward local learning standards and reflect upon how students learn as well as upon their own professional growth. Teachers make discoveries about how students construct meaning of key concepts and skills. They encourage group members to reexamine, clarify, and transform their thinking so that they can help students succeed. 
Journal of English Education, Literature, and Culture

Reader-response criticism is a form of literary criticism which depends on the reader's response to the text. The theory even suggests that the text is impossible to exist without a reader. Reader-response theory recognizes the reader as an active agent who imparts "real existence" to the work and completes its meaning through interpretation. Literature is thus rendered a form of performing art in which each reader creates their own, unique, view of the text. Reader-response criticism also recognizes that the text's interpretation will often depend on the time or occasion when the work is read. At different points in the reader's life, they may take different meaning from the text, often depending on their own life experiences.

\section{Observation of Action}

Based on the result of observation in the second cycle, it was found that there were eight students from ten students $(80 \%)$ who got the progress of capabilities in writing skills. If it was contrasted to test-1, it had higher score with the index of $0.52(66 \%)$. Therefore, it can be said that collaborative writing and reader-response criticism are very effective to develop the creativity of students in writing an intellectual diary.

\section{Reflection on the Observations}

The result of observation in the second cycle found that teaching-learning process was more conducive and creative, students did not hesitate again to ask some questions; and students could travel across the world to make a deep meaning of what connotation and denotation of texts in literary work

\section{CONCLUSION}

One of the chief problems in the study of any literature is to understand the relationship existing between that literature and the social milieu in which it was produced. Therefore, the existence of action research is undeniably true to solve the problem. Action research is a purposeful, yet systematic conducted by teachers for the intent of improving their practice and performance. This ultimately leads to increased student's motivation and academic achievement, as well as improvement in teaching 
Journal of English Education, Literature, and Culture

Here, action research seems to have two essential benefits. First, as the primary audience, students directly benefit from the fresh and innovative strategies used by the teacher. Second, from the results of a focus group engaging in action research, there appears to be a feedback loop that transforms the attitudes and depositions of the classroom teacher. Moreover, it reconstructs our attitudes and beliefs about how students learn. In many cases, teachers have reported an increased confidence in their teaching abilities and more assurance in the methods gained from the research conducted.

Based on the data analyzing, it is concluded that collaborative writing and reader-response criticism can be used to improve the students' capabilities in analyzing any literary work through novels and films. They also develop students' skills in writing of an intellectual diary. After having this research, I see that grades are not the ultimate judge of what students getting out of this class. I no longer view students' minds as containers with me pouring information into them. Action research really validates everything that I do. I know how to collect, to analyze, and to access the data. I am no longer just using my intuition.

\section{REFERENCES}

Anshari, Dadang S. "Peningkatan Kemampuan Menulis Mahasiswa Melalui Model Workshp dalam Perkuliahan Kepenulisan pada Program Nonkependidikan Jurusan Pendidikan Bshasa dan Sastra Indonesia FPBS UPP' Bahasa \& Sastra, Vol 4, No, 6. April 2004.

Fathman, A.K. and E. Whalley. 1990. Teacher Response to Student Writing: Focus on Form versus Content. Ed. B. Kroll. New York: Cambridge University Press

Hernowo. 2003. Quantum Reading. Bandung: Mizan Learning Center.

Huntley, H.S. 1992. Feedback Startegies in Intermidiate and Advanced Second Language Composition. Washington DC: Education Resources Information Center. ERIC Database ED355809.

Laurenson, Diana and Alan Swingewood. 1972. The Sociology of Literature. Great Britain: MacGibbon \& Kee Ltd. 
Journal of English Education, Literature, and Culture

Moon, C., and R.L. Boulon. 1977. Reluctance to Reflect: Issues in Professional Development. Ed. D. Hasyes. London: Prentice Hall

Nunan, D. 1990. Action Research in the Language Classroom. Ed. J. Richards and D. Nunan. Cambridge: Cambridge University Press

Richards, J.C. and C. Lockhart. 1994. Reflective Teaching in Second Language Classrooms. Cambridge: Cambridge University Press

Robert, J. 1998. Language Teacher Education. Cambrige: Cambridge University Press

Truscott, J. 1996. "The Case against Grammar Correction in L2 Writing Classes". Language Learning 46 (2): 327-69

Wallace, M.J. 1991. Training Foreign Language Teachers: A Reflective Approach. Cambridge: Cambridge University Press. 